\author{
Aurelio GonZÁLEZ \\ El Colegio de México \\ agonza@colmex.mx
}

\title{
Luis Rius: poeta, maestro, estudioso y amigo
}

Luis Rius murió en México, nació en España, pero él siempre vivió en la extranjería. El hombre de mirada poética, entrañable para todos los que le rodearon como alumnos, subordinados, colegas y amigos, siempre sintió la nostalgia como parte integral de su ser; nostalgia incluso de aquello que realmente no había conocido en su infancia, como era su pueblo y su país natales. Luis Rius Azcoitia nació en Tarancón, población de la provincia de Cuenca, el 10 de noviembre de 1930, así que era, en el sentido más preciso del término, un "niño de la guerra", ya que en su primera infancia tuvo que enfrentar la violencia, la tensión y las penurias que implica una guerra, más cuando se trata de una contienda fratricida como la Guerra Civil española, y después el desgarramiento del exilio. Éste debido en buena medida a que su padre, Luis Rius $\mathrm{Zu}$ nón, hombre culto e interesado por las tradiciones de su lugar de origen, como militante del Partido Radical Socialista de Marcelino Domingo fue alcalde de su natal Tarancón en 1933, cuando ya se había instaurado la Segunda República española; también fue diputado provincial y presidente de la Diputación de Cuenca en 1934, así como gobernador civil de Soria y Jaén en 1935 y 1936, por lo que al estallar la guerra tuvo que abandonar su tierra.

De su lugar de origen, Luis Rius recordará — con las brumas y fantasía que genera la corta edad en la que se fijó el recuerdo- los campos 
infinitos de horizonte lejano — un horizonte casi inalcanzable —, la tierra reseca por el sol y los grandes silencios de la Castilla eterna. Una tierra castellana similar a la de Machado, poeta a quien dedicó Rius tantos comentarios sensibles y próximos a su poética personal. A fin de cuentas, en su origen él era un castellano, un hombre de la "tierra adentro", de surcos, barbecho, sementeras y campos sembrados, y tal vez para compensar ese sol castellano se entusiasmó hasta lo más profundo de su ser, a través del cante flamenco, por ese otro sol, el de Andalucía, lleno de brillos, resplandores y luz alegre cuando no dramática.

El principio de la extranjería y la nostalgia de Luis Rius dio inicio en octubre de 1936, cuando, como consecuencia de la Guerra Civil y después de un corto periodo en Jaén y Barcelona, fue evacuado junto con su hermana Elisa y su madre a Francia, específicamente a Normandía, tierra de gris profundo, donde permaneció el resto de la guerra española.

En 1939 se trasladó con su familia a México, país en el que vivió de ahí en adelante y donde se estableció definitivamente. En México se formó como ser humano y como poeta, y aquí se convirtió en maestro. Luis Rius se inscribió en la Facultad de Filosofía y Letras de la Universidad Nacional Autónoma de México en 1948, y años después ahí se doctoró en Letras con un trabajo brillante sobre otro poeta caminante: León Felipe.

En la Facultad, la suya y la nuestra, Luis fue discípulo y amigo de maestros como don Amancio Bolaño e Isla, profesor de fonética, gramática histórica, latín; Julio Torri, responsable de la literatura medieval y la francesa, y Francisco de la Maza, brillante especialista en el arte virreinal de México. Como nos dice Arturo Souto, eran los años en que pasaban o estaban permanentemente en la Facultad formando a jóvenes inquietos figuras como Julio Jiménez Rueda, José F. Montesinos, Ermilo Abreu Gómez, Francisco Monterde, José Rojas Garcidueñas, Carlos Pellicer, Alfonso Reyes y los más jóvenes entonces: José Luis Martínez, María del Carmen Millán. En esta época Luis Rius adquirió el rigor académico y la capacidad crítica; esa crítica se convirtió en exigente autocrítica y, como alguna vez comentó su íntimo amigo Arturo Souto Alabarce, fue debido a ella — que lo hacía ser tan exigente- que escribiera y publicara menos poesía de la que su inspiración y creatividad podían generar. 
En esta universidad, su alma máter, muy pronto fue profesor, así como en la Universidad de Guanajuato, en la que dirigió la Escuela de Filosofía y Letras y cuya biblioteca ahora lleva su nombre. También dio clases de literatura, siempre con su encanto particular, en la Universidad de San Luis Potosí, en la Universidad Iberoamericana y en el por aquellos años importante México City College. Fue en 1952 cuando José Rojas Garcidueñas, fundador y director de la Facultad de Filosofía y Letras de la Universidad de Guanajuato, invitó a dar clases a Rius y a otros jóvenes estudiosos (entre ellos Juan Villoro, Horacio López Suárez y Ricardo Guerra). Los recién llegados alquilaron una casa en la calle de Pocitos número 77, y se establecieron entusiastas en una ciudad que iniciaba su despegue cultural; fueron ésos los años de la creación de los Entremeses cervantinos de Enrique Ruelas, otro exponente de la Facultad de Filosofía y Letras de la UNAM. A este grupo iba a unírsele por largas temporadas el siempre trashumante Pedro Garfias, poeta admirado por Rius y los jóvenes de aquella generación de escritores y académicos.

Esa estancia en Guanajuato con aquel grupo de jóvenes profesores hay que verla a la distancia como un gran y valioso intento de descentralizar la educación y la cultura universitaria, generando otros polos académicos y culturales dinámicos y de alto nivel fuera de la capital y sus instituciones consagradas y reconocidas.

Como maestro, Luis Rius era fascinante y capturaba la atención de los alumnos; en este sentido, la pluma de Gonzalo Celorio nos recuerda que

el salón de clase se abarrotaba principalmente de estudiantes del sexo femenino [...] Yo me tenía que sentar en la tarima porque el salón 201 tenía capacidad para sesenta alumnos y entrábamos en él cerca de cien [...] Y si bien es cierto que eran las mujeres las que suspiraban, también es cierto que los hombres quedábamos cautivos en las disertaciones y lecturas del maestro Rius. Oírlo disertar sobre la poesía castellana del Medioevo [...] y leerla una y otra vez, antes de que la memoria, considerada excluyente del entendimiento, cayera en franco desprestigio. Fue la mejor inversión para iniciar nuestro patrimonio poético (462).

Probablemente fue desde que era alumno de Julio Torri, quien daba literatura medieval en la Facultad, cuando Luis Rius se entusiasmó por 
la poesía de Gonzalo de Berceo y sobre todo por la lírica castellana del siglo XIII. Yo recuerdo haber asistido a sus clases de literatura medieval a mediados de los años setenta, cuando ya había encargado buena parte de las horas de la cátedra, con la generosidad y sabiduría que lo caracterizaban, a Graciela Cándano. Lo recuerdo apoyado en el escritorio con la mirada que iba del grupo a la ventana por donde entraba la luz de la tarde que se venía, buscando quién sabe qué lejano horizonte, y su voz se teñía de nostalgia y recordaba el profundo aire melodioso del villancico tradicional y del zéjel, y cómo de ahí desembocaba en los versos de pie quebrado de su admirado Jorge Manrique. El aire se impregnaba de poesía y la Edad Media española se volvía una realidad en la tarde citadina mexicana, y yo quedaba enganchado para siempre por la poesía de Manrique y el mundo medieval.

Muchas veces Luis Rius nos acercó a otros poetas. De Berceo, por ejemplo, apuntaba que la eternidad de sus versos la habían descubierto los poetas, no los eruditos: "Afortunado Gonzalo de Berceo — decía—, ése ha sido el mejor premio a su dulce humildad" (Rius citado por Cándano: 80).

Rius también está en el principio del movimiento de revistas literarias en el paso a la segunda mitad del siglo xx. En 1948, junto con Tomás Segovia y Manuel Durán, entre otros, participó en el nacimiento de la revista Presencia, ejemplo de publicación en la que se evidenciaba el cambio generacional del exilio español, ya que sus fundadores, formados en México, en realidad eran niños o adolescentes cuando se inició su exilio y establecimiento en México, por lo que España era una referencia electiva y cultural. El papel de coordinadores intelectuales de aquella revista lo llevaron Ramón Xirau y Ángel Palerm, pero fue la primera de una serie de publicaciones que incluyeron autores de otras latitudes. Su director fue Jomi García Ascot y se publicó entre 1948 y 1950; también participaron en ella Enrique Echeverría, Francisco González Arámburo, Carlos Blanco Aguinaga, Manuel Durán, Lucinda Urrusti y Roberto Ruiz. En esta misma línea y con Inocencio Burgos, Arturo Souto Alabarce, Alberto Gironella, José Luis González Iroz y otros jóvenes, Rius creó Clavileño, revista ilustrada por Francisco Moreno Capdevila y Arturo Souto cuyo título tenía evidentes resonancias cervantinas e intenciones quijotescas; fue dirigida por el propio Luis 
Rius en los números de mayo y agosto de 1948. Clavileño desapareció después del segundo número, de muerte natural o financiera, como suelen morir tantas revistas jóvenes y universitarias de poéticos nombres. A pesar de ello, la revista amplió el círculo de colaboradores: Manuel Durán, Enrique Echeverría, Horacio López Suárez, Rafael Segovia. Más adelante, en 1951, surgió Segrel, creada también por Rius con Celedonio Martínez Serrano y Francisco de la Maza; la dirigió Arturo Souto Alabarce y constó también de dos números. En 1953 nació Ideas de México, coordinada al principio por Benjamín Orozco y en una segunda época por José Pascual Buxó, y por último Hoja, de una página y dirigida por Tomás Segovia, que duró de 1948 a 1950. En ambas Luis Rius fue colaborador.

La de Rius es una generación que se aglutina en torno a distintas revistas, que de hecho son publicaciones comunes, aunque al comienzo hubo ciertos inicios “independientes”: José Pascual Buxó, Enrique de Rivas y César Rodríguez Chicharro no tenían revista impresa en ese tiempo, y también Tomás Segovia, amigo, pero un poco apartado de todos, en ese mismo año de 1948, el de Clavileño, inició su fina Hoja. Después vendrían nuevas revistas que fueron integrando lo que hoy se conoce como "Generación de medio siglo", la segunda generación del exilio republicano, todos ellos nacidos entre 1927 y 1937 y de hecho la generación "hispanomexicana", pues fue en México donde se formaron y donde escribieron.

Estas revistas tuvieron un claro significado en el desarrollo de nuestros referentes culturales literarios, pues implicaban la integración de lo hispánico con lo nacional en una dimensión amplia y con una perspectiva moderna e internacional.

Rius colaboró también en revistas de más amplia envergadura y vigencia temporal, como Cuadernos Americanos, Anuario de Letras (UNAM), Las Españas, Diálogos, Revista Mexicana de Cultura, suplementos culturales como México en la Cultura, El Heraldo Cultural, y periódicos diarios como El Nacional, Novedades y Excélsior. En este sentido Rius se convirtió en un referente de la cultura y la literatura nacionales. Ello se proyectó aún más con sus programas en Radio Universidad y con la serie de televisión en el Canal 13, llamada sugerentemente Viaje alrededor de una mesa, con sabrosas charlas sobre literatura y cultura en general. 
A la vez tímido y conversador, siempre cordial y mesurado, en torno suyo reunió muchos amigos. Si de cuando en cuando sus ironías podían volverse un tanto cáusticas, había en el fondo de su actitud una bondad natural que lo libraba de toda pedantería. Más que el debate de opiniones contrarias y la polémica, prefería la charla con los amigos en ambientes en los cuales el aire se llenaba con el humo de los cigarrillos (algo habitual en aquellos años), copas de buen o regular vino, corridos de Lucha Reyes y canciones de Agustín Lara o cante jondo, y la voz de Enrique Morente.

Luis Rius se casó dos veces; de su primer matrimonio tuvo tres hijos, y posteriormente, en 1968, se casó con Pilar Rioja, brillante bailarina mexicana de flamenco y de danza española clásica, hija de padres españoles afincados en Torreón, quien fue su musa y a quien dedicó sus, tal vez los únicos, poemas alegres.

En sus poemas destacan el conocimiento de los clásicos, el simbolismo y la contención, muy expresiva en los versos breves. También escribió numerosos ensayos sobre la poesía española medieval y de los Siglos de Oro, del exilio español en México y una gran biografía sobre León Felipe. Además del amor, se puede decir que el tema dominante de su escritura es la identidad.

Sus preocupaciones poéticas fueron fundamentalmente el exilio y el amor, o como él mismo las llama en la antología que hizo de su propia obra: el "Arte de extranjería" y la "Cuestión de amor", ${ }^{1}$ tal como nos dice en su soneto "Acta de extranjería".

¿De qué tierra será?, ¿dónde su mar?

—dicen-, ¿cuál es su sol, su aire, su río?

Mi origen se hizo pronto algo sombrío

y cuando a él vuelvo no lo vuelvo a hallar.

Cada vez que me pongo a caminar

hacia mí pierdo el rumbo, me desvío.

${ }^{1}$ La tercera parte de la antología la llamó "Invención varia" e incluía los poemas de "temas y tonos que me son menos frecuentes y algunos tan sólo ocasionales", "Nota preliminar”, firmada en México, D.F., octubre de 1983 (Rius 1984: 23). 
No hay aire, río, mar, tierra, sol mío.

Con lo que no soy yo voy siempre a dar.

Si acaso alguna vez logré mi encuentro

- fue camino el amor-, me hallé contigo

piel a piel, sombra a sombra, dentro a dentro,

el frágil y hondo espejo se rompió,

y ya de mí no queda más testigo

que ese otro extraño que también soy yo.

(Rius 1984: 76)

En el poema aparecen sus elementos identitarios y contrastantes: la tierra y el mar, pero también una naturaleza que recuerda a fray Luis de León y su búsqueda del hombre interior, sólo que Rius solo se encuentra en el amor y a final de cuentas él es también "ese otro extraño".

No en balde comentó Rius al hablar sobre su condición hacia 1965, cuando regresó a España por primera vez:

Somos desterrados. Y si ahora, porque vivimos en México, sentimos un poco que nos falta el sustento de España, mañana, si el caso se da, porque vivimos en España, sentiremos en el mismo grado que nos falta el sustento de México. El destierro no nos lo da ya ni nos lo quita ninguno de los dos países porque no está en ellos sino en nosotros, formando parte de nuestro ser (1965: 16).

Volvió a España varias veces, y una de ellas permaneció un año y medio. Intensísimas emociones, muchos reencuentros, pero el hecho es que estando en España, vuelto a su origen y punto de partida, se encontró ahí también con el mismo, profundo sentimiento de dualidad existencial que no desaparecía por cambiar de latitud. Luis Rius, por tanto, como otros muchos seres, era un hombre "fronterizo". En estos sentimientos generados por una pertenencia y una nostalgia que se intercambian, con todo lo que pueden tener de luz y sombra, de ilusión y de tortura, es posible que esté la génesis de buena parte de su poesía, pero no es más que eso: punto de partida, su concepción personal de lo que él llama "arte 
de extranjería" no se limita a la simple circunstancia geográfica, que a fin de cuentas puede ser algo accidental. Se trata, a decir verdad, de una concepción trascendente de la existencia que él expresa en poemas que son en realidad metafísicos, que pasan de la vivencia y experiencia personal y por tanto individual, a una reflexión sobre el lugar del individuo en el mundo y de su extrañamiento de éste.

Rius escribió sólo cuatro poemarios: Canciones de vela (Segrel, 1951), Canciones de ausencia (Universidad de Guanajuato, 1954), Canciones de amor y sombra (ERA, 1965), Canciones a Pilar Rioja (Finisterre, 1969) y una antología compilada con textos anteriores revisados por él y algunos nuevos, concluida en octubre de 1983, pocos meses antes de su muerte, intitulada Cuestión de amor y otros poemas (Promexa, 1984), ${ }^{2}$ y los ensayos El mundo amoroso de Cervantes y sus personajes (1954), Los grandes textos de la literatura española hasta 1700 (1966) y León Felipe, poeta de barro. Biografía (1968).

$\mathrm{Su}$ primer poemario, Canciones de vela, tiene un título de origen medieval pues se refiere a unas supuestas canciones que entonaban los guardias en su vigilancia nocturna. En el prólogo a sus versos dice Rius: "lector, con timidez que no quiere ser desconfianza, pongo en tus manos estas canciones de vela. La confusión de mis sentimientos al hacerlo es grande. No podría explicarte por qué raro fenómeno, mi temor se trueca en esperanza o mi firmeza en incertidumbre: curioso retablo de contradicciones que me desanima y alienta a la vez" (1951: 7). En estos poemas ya está presente con madura claridad su sentimiento resignado que se enfrenta a lo que no se puede superar, da lo mismo que sea el mar o la muerte misma. Siempre dicho desde esa gran conciencia del yo, del ser y el hacer. El hombre que simplemente vive:

Soy yo otra vez y es el mar

quien me guarda nuevamente.

Muere la tarde. Reposa

el viento. El silencio duele.

${ }^{2}$ Vuelto a editar en 1994: Luis Rius, Cuestión de amor y otros poemas, pres. Pedro Cerrillo, pról. Ángel González, est. José Paulino, Cuenca, Universidad de Castilla-La Mancha, 1994. 
Soy yo otra vez que he venido como ayer, mañana y siempre, con mi destierro a la espalda a soñar.

Soy yo otra vez que he venido paso a paso, como siempre, por ver si no encuentro el mar y es el mar quien me detiene. Otra vez yo. Vedme aquí esperando eternamente, con mis cabellos de sal azotándome la frente.

Soy yo otra vez y es el mar quien me guarda nuevamente.

(Rius 1984: 30)

El hombre de la tierra adentro llega al mar, se aleja de su destierro para llegar a una frontera que no puede traspasar y que lo detiene. Es un eterno retorno al punto de espera donde siempre se encuentran el hombre y el mar: mar en eterno movimiento y hombre en eterna espera. La otra gran cuestión de su obra poética es la del amor. A veces un amor desdichado, tal vez coincidente con su vida misma es el que surge de su segundo poemario, publicado en su estancia guanajuatense con el significativo título de Canciones de ausencia. Tras un silencio de casi diez años, y ya de nuevo en la ciudad de México, publica en 1965 Canciones de amor y sombra, en las cuales desde luego que el amor es una línea conductora, pero también es paralela al desamor y a la muerte, a los amigos idos y a los poetas muertos. Hay glosas y reminiscencias del cancionero tradicional hispánico y poemas de amor sencillos, en hexasílabos tradicionales de los que surge una frágil conciencia de lo etéreo del amor, pero también de la vida que se queda vacía:

Se quedó la estrella

fija en aquel cielo.

En aquella rama,

la flor. En el viento 


aquel quedó el pájaro
siempre prisionero.
Tu adiós infinito,
en mi pensamiento;
tu llanto, en mis labios;
tu voz, en mi sueño.
Y el corazón mío,
como un olvidado
y sombrío huerto,
sin ave ni estrella,
sin flor y sin cielo,
el corazón mío
se quedó desierto.

(Rius 1965: 17)

La flor, el pájaro, la estrella, el huerto: tópicos cuya resonancia viene de la poesía tradicional. La tristeza que se asume casi estoicamente. Sin embargo, quedan el silencio y el adiós infinito en el pensamiento.

En la última de sus colecciones de poemas, Canciones a Pilar Rioja (1969), el tono es otro, aunque las preocupaciones pueden ser las mismas. Es un canto profundo, alegre, admirado y erótico por la "bailarina", por Pilar, y lo expresa con el mejor lenguaje barroco, tal vez en concordancia con la danza de Pilar Rioja, flamenca, quien llevó la danza española barroca, aunando castañuelas y Boccherini, a una cumbre escénica. Así ve Rius a Pilar al danzar, y lo expresa con poéticas antítesis barrocas:

Ser y no ser de aire. Ser de tierra para, al cabo, no serlo. Ser de fuego sin ser fuego, y de pronto, transparente es agua ya, y no es agua tampoco. Alza Pilar los brazos, las serpientes que se yerguen al ascua de la música; quieren volar y bellas se desploman, mariposas las manos incendiadas.

(1970: 19) 
En este sentido, el uso del lenguaje barroco es muy natural en Luis Rius, pues el poeta no se fracciona del estudioso de la literatura clásica española, y por tanto no hay que olvidar que "cuando Luis Rius se acerca a los poetas [...] españoles del pasado, no está repitiendo sino recreando, continuando, revitalizando una larga tradición, estableciendo un diálogo con otras voces lejanas que resuenan en la suya" (González: 21).

Yo asistí a las clases de Luis Rius en la Facultad, pero ya lo conocía desde antes, en tertulias en casa de amigos como Paco Ignacio Taibo o Miguel Ángel Merodio, con Inocencio Burgos y otros escritores o artistas. También desde la Revista de Bellas Artes, de la cual yo era secretario de redacción, donde habíamos estado en contacto a propósito de León Felipe y de Antonio Machado. Pero fue en el escenario donde se estrechó nuestra amistad. Él, apasionado por el flamenco y por la danza de Pilar, no podía haber permanecido al margen de su realización escénica, y así participó en la creación de dos libretos para espectáculos de Pilar Rioja: Teoría y juego del duende (1972), Mística y erótica del Barroco (1977).

Teoría y juego del duende es una selección de textos de Luis Rius en la cual volcó su pasión, sentido y entendimiento del flamenco y el Barroco, con partes de la famosa conferencia de Federico García Lorca del mismo nombre y versos del Romancero y de obras de teatro de Lorca y de Machado. Esta obra narra literaria y coreográficamente cómo se va pasando del Ángel a la Musa y así hasta llegar al Duende, obviamente intercalando los textos y las danzas. En el espectáculo intervenían dos actores, una orquesta de cámara para la primera parte, piano y cantante clásica la segunda, y guitarras flamencas y cantaores, dos actores y la bailarina en la tercera. La música era de Bach, Corelli, Paganini, El Vito de Nin, Café de Chinitas, Sevillanas boleras y Anda jaleo, de Federico García Lorca, y flamenco: tangos de El Piyayo, y la farruca y la seguiriya. Originalmente estuvo dirigido por Rafael López Miarnau, con escenografía de dibujos por Héctor Xavier, iluminación de Antonio López Mancera, la Orquesta de Cámara de la Ciudad de México, la soprano Guillermina Higareda, el cantaor Antonio de Córdoba, las guitarras de Lorenzo y Sergio Fernández y la poesía dicha por Aurora Molina y Luis Rius. Este programa se presentó varias veces en el Palacio de Bellas Artes y en el primer Festival Cervantino, en 1972. Hubo varias funciones 
de preparación del espectáculo antes de la presentación en el Cervantino; en una de ellas, en el Centro Asturiano, obviamente sin el gran aparato de orquesta, yo me encargué del aspecto técnico y escénico, con lo cual Luis y yo nos alejamos de nuestras actividades, él en la Facultad y yo en el Instituto Nacional de Bellas Artes, y nos volvimos simplemente teatreros, compañeros de las tablas mientras la bailarina llenaba el aire con su arte y Luis con su voz y los poemas de la tradición.

El otro libreto en el que tuvo parte Luis Rius fue Mística y erótica del Barroco, que desde su concepción fue pensado para tres figuras en escena: una Primera Bailarina, una Primera Actriz y un Primer Actor. El espectáculo se creó para su presentación en la iglesia de san Francisco Javier en Tepotzotlán, donde inició su andadura por diversos foros del país y del extranjero.

De las doce danzas que interpretaba Pilar Rioja en este espectáculo, algunas son de corte popular (el Villano y las Sevillanas), y la mayoría de inspiración cortesana con música de compositores españoles e italianos del Barroco como Vivaldi, Corelli, Marcello, Boccherini, Soler y Mateo Albéniz. Las escenas que integraban el espectáculo, siete en total, se iban intercalando con las danzas y tenían matices muy variados que iban de lo burlesco a lo grave, todo ello entremezclado con textos de santa Teresa, san Juan de la Cruz, el conde de Villamediana y otros autores tanto del Renacimiento como del Barroco. Los poemas habían sido escogidos por Luis Rius, el vestuario fue de Guillermo Barclay y la dirección de Rafael López Miarnau, con coreografías de Pilar Rioja. Así era Luis Rius, un hombre polifacético: estudioso de la literatura, maestro, editor, difusor de la cultura y hombre cercano al espectáculo.

Ya en los años ochenta, una noche en Madrid, saliendo de cenar, me encontré con Luis Rius, y desde luego, nos sentamos a platicar; hablamos de España, de cómo veíamos a México en la distancia, de León Felipe y nuestro mutuo gusto por un libro como Versos y oraciones de caminante, y claro, terminamos hablando del Romancero, de cómo esa poesía estaba tan cercana a nosotros, tan cercana que casi nos parecía algo natural, como cuando los niños hacen poesía sin darse cuenta; y me contó cómo había escuchado a una pequeña que se había mojado decir que la había alcanzado, sin saber cómo, una gota de nube. Así era 
Luis, siempre nostálgico y poético, pero esencialmente poeta, y en este sentido habría que recordar con Arturo Souto que

nunca escribió por sistema, por disciplina de trabajo. Cazador al vuelo: una vivencia, una palabra, una idea, un pretexto para que el poema naciera hecho, completo, armado de todas sus armas. Vendría después la primera lectura - el oído sobre todas las cosas - atenta, alerta, preocupada, el vocablo que suena o disuena, su precisión, su poder evocador, pero todo ello resulta ya secundario. Primero ha tenido que darse la intuición, la visión total del poema antes de ser dicho, de ser escrito (126).

Luis Rius falleció en la ciudad de México el 10 de enero de 1984, dejando desolada la Facultad y a todos los que lo conocimos con un hueco muy difícil de llenar y que, a treinta años de distancia, hoy revivimos.

Pero él nos advirtió de esta ausencia cuando nos dijo:

$$
\begin{aligned}
& \text { Cuando yo muera, todo } \\
& \text { será silencio, viento, ausencia. } \\
& \text { No quedará ni una canción tan sólo } \\
& \text { que al amor le recuerde cómo era. }
\end{aligned}
$$

Y así ha sido.

\section{BIBLIOGRAFÍA}

Cándano, Graciela. "Últimas conversaciones con el poeta Luis Rius", en Utopías, 6 (marzo-abril 1990): 80.

Celorio, Gonzalo. "Luis Rius, corazón desarraigado", en Poesía y exilio. Los poetas del exilio español en México. México: El Colegio de México, 1995: 461-468.

González, Ángel. "Prólogo", en Cuestión de amor y otros poemas. México: PROMEXA, 1984: 15-28.

Rius, Luis. Canciones de vela. México: Segrel, 1951.

Rius, LuIs. Canciones de amor y sombra. México: ERA, 1965.

Rius, Luis. "Poesía española en México", en Revista de la Universidad de México, XXI: 5 (1967): 12-16. 
Rius, Luis. Canciones a Pilar Rioja. México: Finisterre, 1970.

Rius, LuIs. Cuestión de amor y otros poemas. México: PROMEXA, 1984.

Souto Albarce, Arturo. "Vida y poesía de Luis Rius", en La Experiencia Literaria, 12-13 (2005): 117-128. 